\title{
UTILIZAÇÃO DE ENXERTO HEPÁTICO COM SCHISTOSOMA MANSONI: RELATO DE UM ACHADO INESPERADO
}

\author{
Use of liver graft with Schistosoma mansoni: report of an unexpected finding \\ Olival Cirilo Lucena da Fonseca Neto, Renatha Inácia Parente, Priscylla Rabelo, Paulo Sérgio Vieira de Melo, \\ Américo Gusmão Amorim, Norma Jucá, Cláudio Moura Lacerda.
}

\section{RESUMO}

Introdução: O aumento no número de transplantes realizados e o uso de enxertos de doadores limítrofes têm levado à identificação de agentes infecciosos, como o Schistosoma mansoni, em enxertos de doadores assintomáticos e que não eram diagnosticados antes do transplante. Dessa forma, o presente trabalho visa descrever o relato de caso de uma paciente que recebeu enxerto hepático com Schistosoma mansoni, não comprometendo o resultado do transplante hepático no pós operatório mediato.

Descritores: Esquistossomose, Transplante de Fígado, Doadores de Tecidos.

Instituição:

Serviço de Cirurgia Geral e Transplante Hepático do Hospital Universitário Oswaldo Cruz - HUOC, Recife, PE, Brasil.

\section{Correspondência:}

Olival Cirilo Lucena da Fonseca Neto

Rua Jacobina,45,1002, CEP-52011-180. Recife-PE.

Tel.: (81) 99989-0208

E-mail: olivalneto@globo.com

\section{INTRODUÇÃO}

A esquistossomose mansoni é uma doença infectoparasitária provocada pelo trematódea do gênero Schistosoma ${ }^{1}$ e afeta aproximadamente 240 milhões de pessoas em todo o mundo. ${ }^{2}$ No Brasil, é endêmica em vasta extensão do território, destacando-se a Região Nordeste, que apresenta uma das maiores prevalências do país. ${ }^{1}$

Os seres humanos são geralmente infectados quando as larvas, em água doce contaminada, penetram na pele. Os vermes adultos produzem ovos que podem permanecer alojados no fígado, induzindo uma resposta imune granulomatosa, inflamação crônica, fibrose grave e hipertensão portal. ${ }^{3-6}$ 
Utilização de enxerto hepático com schistosoma mansoni: relato de um achado inesperado

O aumento no número de transplantes realizados e o uso de enxertos de doadores limítrofes têm levado à identificação de agentes infecciosos como o Schistosoma mansoni, em enxertos de doadores assintomáticos e que não foram diagnosticados antes do transplante. ${ }^{7,8}$ Dessa forma, o presente trabalho visa descrever relato de caso de uma paciente que recebeu enxerto hepático com Schistosoma mansoni, um achado inesperado observado posteriormente na biópsia do enxerto.

\section{RELATO DE CASO}

Paciente do sexo feminino, 44 anos, procedente de Campina Grande - PE, com história de icterícia de padrão colestático por aproximadamente dois anos, diagnosticada com colelitíase e coledocolitíase. Foi submetida à laparotomia(Kocher) para tratamento da doença litiásica biliar, que resultou apenas em uma biópsia hepática, evidenciando material de coloração esverdeada, com crescimento neoplásico nodular, concluindo-se adenoma hepatocelular sem atipias celulares. Dois anos após, foi submetida à segunda laporotomia, realizando-se colecistectomia e derivação biliodigestiva, além de nova biópsia hepática, devido ao aspecto cirrótico. $O$ anatomomatológico descreveu tecido hepático castanho-esverdeado compatível com cirrose hepática. Paciente evoluiu nos anos seguintes com desconforto abdominal, icterícia intensa, astenia aos mínimos esforços, desorientação, acolia fecal, prurido, colúria, epistaxe, edema e dor em membros inferiores.

Foi indicado transplante hepático, com diagnóstico de cirrose criptogênica e colestase crônica, apresentando MELD (Model for End-Stage Liver Disease) 19 e CHILD PUGH C no momento do transplante. Constatou-se, em exames laboratoriais, pré-operatórios AST (155U/L), ALT (101U/L), BT (11.3mg/dL), BD (9.6mg/dL), DHL (263 U/L), GGT (362U/L), FA (286U/L), fibrinogênio (339mg/ $\mathrm{dL})$, lactato $(1.6 \mathrm{mg} / \mathrm{dL})$, INR (1.32), PT(7.4g/dL), ALB (2.2g/dL), $\mathrm{Cr}(0.5 \mathrm{mg} / \mathrm{dL})$. A biópsia do fígado explantado concluiu cirrose hepática de padrão biliar compatível com Colangite esclerosante primária.

O doador do enxerto hepático, de 41 anos, procedente de Pernambuco, teve como causa de óbito AVC Hemorrágico, não apresentava qualquer alteração laboratorial e clínica significativa, assim como fígado de aspecto normal no momento da cirurgia de captação. Foi realizada biópsia padrão durante a cirurgia de backtable. O resultado anatomopatológico do fragmento hepático concluiu a presença de esquistossomose hepática, com arquitetura lobular preservada, preservação da tríade, espaço-porta com leve fibrose, infiltrado inflamatório linfocitário com eosinófilos e focos de granuloma e ovo de Schistosoma mansoni, com halo linfocitário e eosinofílico (Figura 1). Vale salientar que os resultados das biópsias são apenas revelados em algum momento do pós-operatório imediato, portanto, não influenciando a aceitação ou não do órgão para transplante.

Otransplantehepáticofoi realizado comatécnica Piggyback e reperfusão retrógrada. Realizada reconstrução portal com anastomose renoportal com enxerto venoso de ilíaca (doador falecido) sem intercorrências. Anastomose arterial e biliar (hepaticojejunostomia) realizadas a seguir de maneira usual. A paciente evoluiu no primeiro dia póstransplante hepático com AST (530U/L), ALT (416U/L), BT (6.5mg/dL), BD (5.3mg/dL), DHL (909U/L), GGT (174U/L), FA (144U/L), fibrinogênio (194mg/dL), lactato $(1.9 \mathrm{mg} / \mathrm{dL})$, INR (3.25) PT(4.7g/dL), ALB (2.0g/dL), Cr (0.7mg/dL). Não foram observadas complicações no pós-operatório imediato decorrentes de infecção por esquistossomose, assim como não foi iniciado tratamento com praziquantel. Foi instituído esquema tríplice de imunossupressão padrão (tacrolimus, prednisona e micofenolato de mofetila) e a paciente recebeu alta com cinco dias de pós-operatório.

Figura 1 - Anatomopatológico do fragmento hepático

A

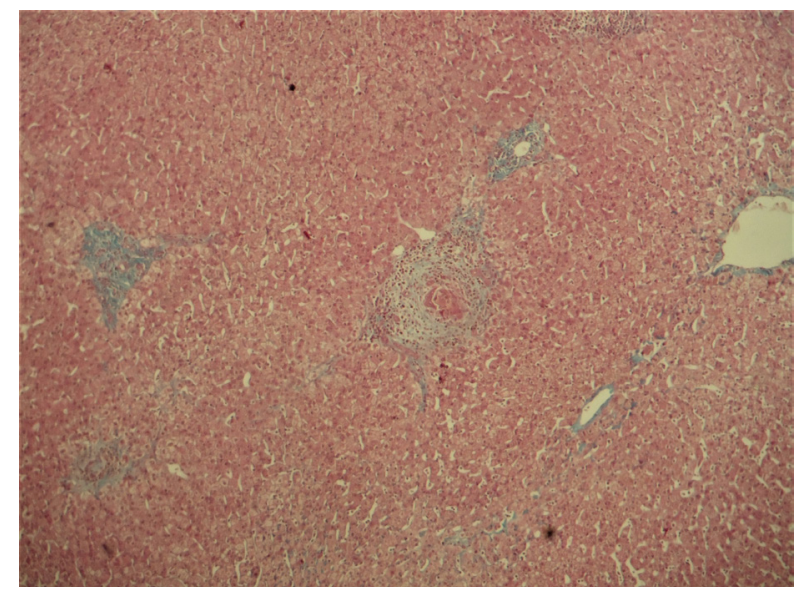

B

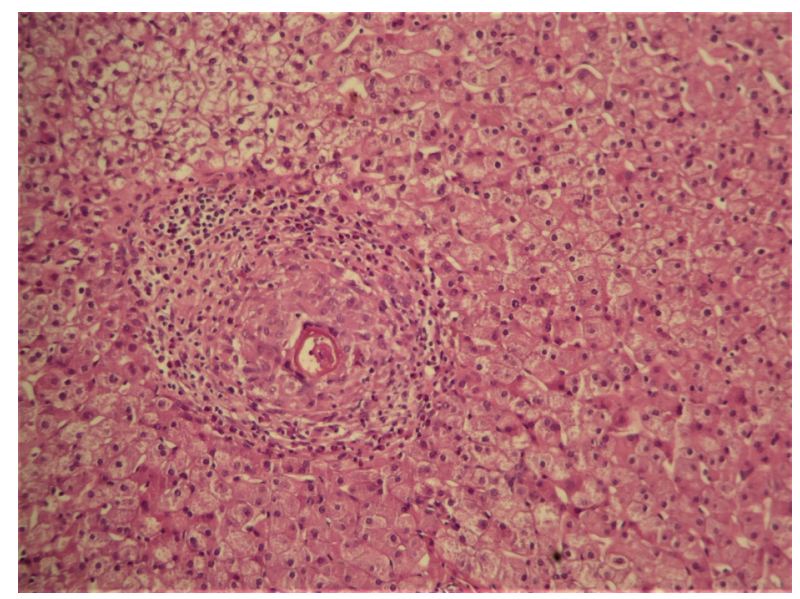



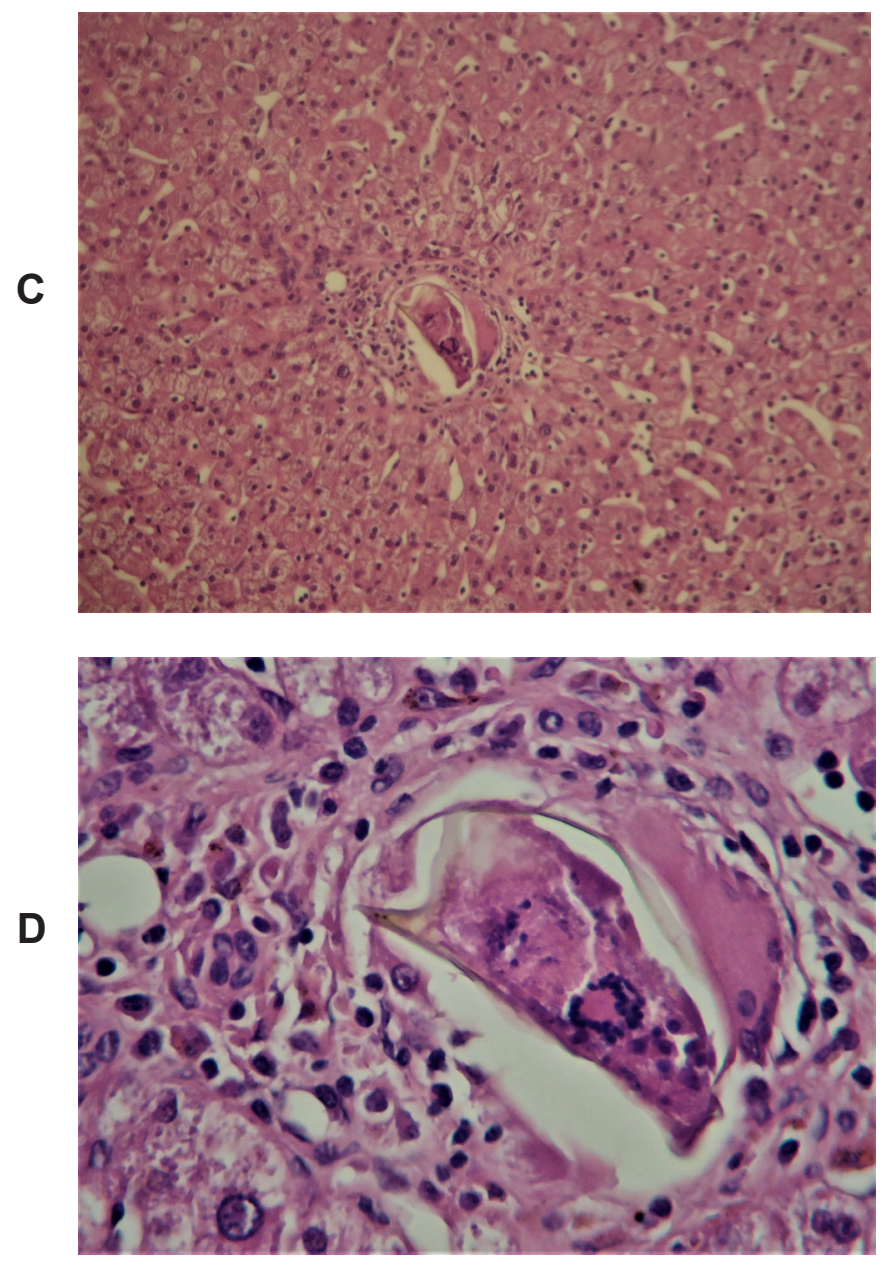

A- Tecido hepático com arquitetura preservada, leve fibrose portal e granulomas esquistossomóticos.

B- Granuloma epitelioide rico em eosinófilos, em torno do ovo de Schistossoma mansoni.

C-Reação giganto-celular em torno de ovo viável de Schistossoma mansoni.

D- Detalhe da espícula característica do ovo de Shistossoma mansoni.

\section{DISCUSSÃO}

Nas regiões endêmicas da esquistossomose, a forma predominante da doença é a esquistossomose crônica, resultante da exposição repetida a cercárias infecciosas. Nessas regiões, quase todos os residentes de longa duração são infectados com esquistossomos em algum momento de suas vidas; cerca de 60 a $80 \%$ de crianças em idade escolar e 20 a $40 \%$ dos adultos podem permanecer ativamente infectados. ${ }^{9}$

A esquistossomose aguda ocorre mais frequentemente em viajantes ou imigrantes para regiões endêmicas, expostos a antígenos do esquistossomo pela primeira vez mais tardiamente que o usual. Essa forma é, muitas vezes, referida como síndrome Katayama, uma reação de hipersensibilidade sistêmica contra a esquistossomose migratória e os ovos. Em muitos casos, no entanto, as infecções agudas são referidas como assintomáticas..$^{10,11}$

O padrão ouro para diagnóstico da esquistossomose hepática é o exame microscópico dos ovos no tecido, mas não muito utilizado devido à natureza invasiva do procedimento. Outras alternativas podem resultar em falso negativos, quando se há um número reduzido de ovos.12,13 Estima-se que há um subdiagnóstico, diminuindo substancialmente a notificação da infecção, assim, o número de pessoas com esquistossomose poderia estar próximo de 440 milhões. ${ }^{14}$

Considerando-se a extensa subnotificação, tem sido descrito o achado, incidental, de enxertos com Schistosoma mansoni, de doadores não diagnosticados antes do transplante..$^{7,8,15-17}$ Nesse relato, foi observado, assim como em trabalhos anteriores, uma boa evolução da paciente que recebeu o enxerto com Schistosoma mansoni, ${ }^{7,8,15-17}$ não sendo estabelecido de imediato tratamento com praziquantel, droga de escolha para o tratamento da esquistossomose, posto que essa droga geralmente não afeta os ovos e os vermes imaturos e atua apenas contra os vermes adultos. ${ }^{18}$

Andraus et al ${ }^{19}$ descreveram um transplante intencional utilizando enxerto de doador com esquistossomose, em um transplante intervivos, sem complicações, em dois anos de pós-operatório. Durante os primeiros estágios da doença, a função hepática é preservada e o paciente assintomático, ${ }^{7}$ o que encoraja o uso de enxertos de doadores com Schistosoma mansoni em um contexto de limitação ao transplante, devido à escassez de doação de órgãos e ao uso de enxertos de doadores limítrofes. ${ }^{20}$

\section{CONCLUSÃO}

Conclui-se que o uso do enxerto hepático com Schistosoma mansoni parece não comprometer a sobrevida do paciente e do enxerto, estimulando sua aceitação entre órgãos limítrofes. 


\section{ABSTRACT}

The increasing amount of transplants performed along with the use of marginal donor grafts have led to the identification of infectious agents, such as Schistosoma mansoni, in asymptomatic donor grafts which had not yet been diagnosed before being transplanted. Thus, the present study aims to describe the case report of a patient who received a liver graft with Schistosoma mansoni, not compromising the result of liver transplantation in the mediate postoperative period.

Keywords: Schistosomiasis, Liver Transplantation, Tissue Donors.

\section{REFERÊNCIAS}

1. Ministério da Saúde (BR), Secretaria de Vigilância em Saúde, Departamento de Vigilância Epidemiológica. Vigilância da esquistossomose mansoni. Diretrizes técnicas. Brasília (DF): Ministério da Saúde; 2014.

2. World Health Organization. [homepage na Internet] Shistosomiasis. [acesso em 2018] Disponível em: https:// www.who.int/schistosomiasis/disease/en/

3. Pearce EJ, MacDonald AS. The immunobiology of schistosomiasis. Nat Rev Immunol. 2002;2:499-511.

4. Fairfax K, Nascimento M, Huang SC, Everts B, Pearce EJ. The responses in schistosomiasis. Semin Immunopathol. 2012;34:863-71.

5. Peterson WP, Von Lichtenberg F. Studies on granuloma formation. IV. In vivo antigenicity of schistosome egg antigen in lung tissue. J Immunol. 1965; 95: 959-65.

6. Burke ML, Jones MK, Gobert GN, Li YS, Ellis MK, McManus DP. Immunopathogenesis of human schistosomiasis. Parasite Immunol. 2009;31:163-76.

7. Vicenzi R, Neto JS, Fonseca EA, Pugliese V, Leite KRM, R $M$, et al. Schistosoma mansoni infection in the liver graft: The impact on donor and recipient outcomes after transplantation. Liver Transplantation. 2011;17:1299-303.

8. Pungpapong S, Krishna M , Abraham SC, Keaveny AP, Dickson RC, Nakhleh RE. Clinicopathologic findings and outcomes of liver transplantation using grafts from donors with unrecognized and unusual diseases. Liver Transplantation. 2006;12:310-5.

9. Stothard JR, Sousa-Figueiredo JC, Betson M, Green HK, Seto EY, Garba A, et al. Closing the praziquantel treatment gap: new steps in epidemiological monitoring and control of schistosomiasis in African infants and preschool-aged children. Parasitology. 2011;138:1593-606.
10. Centers for Disease Control and Prevention. Schistosomiasis. Travelers' health: yellow book, health information for international travel. Atlanta: 2005.

11. Ross AG, Vickers D, Olds GR, Shah SM, McManus DP. Katayama syndrome. Lancet Infect Dis. 2007;7:218-24.

12. Schwartz BS, Mawhorter SD, AST Infectious Diseases Community of Practice. Parasitic infections in solid organ transplantation. Am J Transplant. 2013;4:280-303.

13. Hoare M, Gelson WT, Davies SE, Curran M, Alexander GJ. Hepatic and intestinal schistosomiasis after orthotopic liver transplant. Liver Transpl . 2005;11:1603-7.

14. Colley DG, Bustinduy AL, Secor WE, King CH. Human schistosomiasis. Lancet. 2014;383:2253-64.

15. Brasil IRC, Nepomuceno LR, Schüller RT, Esmeraldo TM, Esmeraldo RM, Esmeraldo RM. Esquistossomose hepática como achado ocasional de fígado de doador para transplante. Medicina (Ribeirão Preto). 2013;46:178-82.

16. Ravi A Patel, Oscar w Cummings, Richard S Mangus, Parth M Patel, Santosh Nagaraju, A Joseph Tector et al. Incidental Schistosomiasis in Transplant Liver: A Case Report and Review of the Literature. Journal of Transplantation Technologies \& Research. 2015; 5:150-5.

17. Pannegeon V; Masini, JP; Paye, François C, Olivier G, Pierre M. Schistosoma Mansoni Infection and Liver Graft. Transplantation. 2005;80:287.

18. Ross AG, Bartley PB, Sleigh AC, Olds GR, Li Y, Williams GM, et al. Schistosomiasis. N Engl J Med. 2002;346:1212-20.

19. Andraus W, Pugliese V, Pecora R, D'Albuquerque LA et al. Intentional Use of Schistosoma mansoni-Infected Grafts in living Donor. Liver Transplantation. 2012;18:867-8

20. Fonseca Neto OCL. O doador limítrofe no transplante hepático. Brasília Med. 2011;48:65-9. 